\title{
Disease Incidence and Ascospore Dispersal from Cut Hazelnut Branches Colonized by Anisogramma anomala
}

\author{
S. Heckert, J. W. Pscheidt, and S. A. Cluskey, Department of Botany \& Plant Pathology, Oregon State University, Corvallis 97331
}

\begin{abstract}
Heckert, S., Pscheidt, J. W., and Cluskey, S. A. 2014. Disease incidence and ascospore dispersal from cut hazelnut branches colonized by Anisogramma anomala. Plant Dis. 98:834-838.

Hazelnut branches bearing stromata of Anisogramma anomala cut in December (2009 and 2010) were compared with branches cut prior to bud break in March to investigate these sources of inoculum. Branches were placed into brush piles (sources). Spore traps and potted hazelnut trees were placed adjacent to each source, $6.4 \mathrm{~m}$ upwind and downwind, and $20 \mathrm{~m}$ downwind from each source. Significantly more ascospores were detected near sources of branches cut in March compared with December in 2010 however, no differences were detected between pruning treatments in 2011. Ascospore viability, as assessed by trypan

cantly more ascospores were detected $6.4 \mathrm{~m}$ downwind compared with $6.4 \mathrm{~m}$ upwind or $20 \mathrm{~m}$ downwind of a source both years. All potted trees exposed to branches from both pruning treatments within sources became diseased both years. The proportion of potted trees that became infected was greater for the downwind group than the upwind for both years, suggesting that ascospores were dispersed beyond the rain splash dispersal range of sources. Ascospores from diseased branches pruned in December or March remained viable, infectious and were dispersed at least $20 \mathrm{~m}$ downwind.
\end{abstract} blue stain, averaged $50 \%$ for both pruning times each season. Signifi-
Anisogramma anomala (Peck) E. Müll. (Diaporthales) is the causal agent of eastern filbert blight (EFB) on European hazelnut (Corylus avellana L.) in the Pacific Northwest (7). The disease was first reported in Washington in 1973 and subsequently has spread southward into Oregon's major hazelnut production area, the Willamette Valley $(19,20)$. EFB is a perennial branch canker with a sunken appearance due to the death of the cambium layer (7). Stromata and perithecia of the pathogen develop in cankers and release ascospores during rain events, starting in early winter and continuing through the spring (18). Ascospores from diseased trees are actively discharged and dispersed with the prevailing storm track (15). Previous studies have shown that only juvenile tissues are susceptible to infection by ascospores $(15,22)$. Therefore, hazelnut trees are most susceptible to infection from bud break (March) until the cessation of terminal shoot growth (July to August) $(17,18,22)$. Ascospore infection, however, typically occurs during rainy periods from bud break through early shoot growth (March to May) (15).

A. anomala is a biotrophic parasite and needs a living host to grow (23) but not necessarily to release ascospores. Ascospore release will continue when cankers are cut from actively growing branches but no definitive time frame is known for cessation in the field (18). Temperature and alternating wet/dry cycles have had an effect on ascospore release from diseased cut branches in a mist chamber study (18) and viscous fluid has been observed seeping from stromata after a wetting period (7), suggesting passive dispersal of ascospores (5). However, it is not known whether active discharge of ascospores continues after the branches have been cut from hazelnut trees and whether those ascospores could be sources of viable inoculum beyond a 4-m rain-splash dispersal range (6).

Current cultural management recommendations for EFB include destruction of diseased branches prior to bud break in order to destroy all potential inoculum sources (11). Growers of susceptible

Corresponding author: S. Heckert,

E-mail: heckerts@science.oregonstate.edu

Accepted for publication 10 January 2014.

http://dx.doi.org/10.1094/PDIS-06-13-0631-RE

(C) 2014 The American Phytopathological Society cultivars, such as the widely planted 'Barcelona' (3), scout for disease symptoms during the winter months, prune 0.6 to $0.9 \mathrm{~m}$ below visible symptoms, and typically burn diseased branches (11). There are strict regulations on agricultural burning in Oregon, and future legislation may lead to the discontinuation of agricultural burning in many areas (4). In the absence of data on whether colonized branches pruned from trees are sources of inoculum, the risk associated with inoculum originating in brush piles is unknown.

The current study focused on whether diseased brush piles are a source of inoculum. Our objective was to determine whether timing of dormant season branch pruning influenced ascospore release, viability, and dispersal of ascospores from brush piles and subsequent hazelnut tree infection. A preliminary report related to this subject has been published (10).

\section{Materials and Methods}

Ascospore collection. Two brush piles, each containing branches cut at different times of the year, were set out in a paired design to investigate differences in ascospore release, viability, and dispersal. The two treatments consisted of hazelnut branches with mature stromata of $A$. anomala cut 10 to 12 weeks before bud break (early pruning treatment) or cut immediately before bud break (late pruning treatment). Branches for both treatments were cut from severely diseased 'Ennis' hazelnut trees in Marion County, OR. Only living branches with mature stromata of $A$. anomala were cut for the experiment. Early-pruning-treatment branches were cut on 16 December 2009 and 16 and 17 December 2010 and positioned in brush piles on 30 December 2009 and 2010, respectively. Late-pruning-treatment branches were cut on 20 and 22 February 2010 and 2 and 4 March 2011 and positioned in brush piles on 2 March 2010 and 7 March 2011, respectively.

Each treatment (early versus late) was replicated three times for a total of six experimental units. Each brush pile contained 125 diseased branches arranged in an approximately 1-by-1-m area that was considered a source (Fig. 1), and gravity-type spore traps (described below) were positioned in the center of each source. A single spore trap was placed $6.4 \mathrm{~m}$ southwest $\left(225^{\circ}\right)$ of the source, designated as "upwind" of the brush pile, to monitor ascospores that may come from an unknown outside infestation. Two additional spore traps were placed at 6.4 and $20.1 \mathrm{~m}$ northeast $\left(45^{\circ}\right)$ of the source, designated as "downwind" of the brush pile, to monitor 
dispersal of ascospores from each source (Fig. 1). Spore traps were positioned relative to the southwesterly spring storm track that is prevalent in the Pacific Northwest (15). The distance of $6.4 \mathrm{~m}$ from sources was selected so that non-source spore traps would be outside the range of rain-splash dispersal of ascospores (6).

For both years (2010 and 2011), experimental units were positioned at six sites at the Oregon State University Botany and Plant Pathology Field Laboratory near Corvallis. The six locations were spaced from each other to keep cross contamination between experimental units to a minimum. In each replicate, both treatment sources were within 75 to $250 \mathrm{~m}$ from each other, and the distance between replicates was 150 to $400 \mathrm{~m}$ from each other. There were other infestations of A. anomala in the immediate area but they were downwind of the prevailing storm track relative to the experimental units.

The gravity-type spore traps within and around the source piles collected ascospores that landed on the surface of the trap during rainy periods $(8,16)$. The spore traps were constructed from $0.86-$ cm-diameter PVC pipe that was $238.7 \mathrm{~cm}$ long, leaving $20.3 \mathrm{~cm}$ intact on one end and sawing longitudinally for $218.4 \mathrm{~cm}$ to make a semicircular trough with a surface area of $635.5 \mathrm{~cm}^{2}$ (Fig. 1). Spore traps were orientated west to east, with the west end at 81.3 $\mathrm{cm}$ above ground level and the east end $48.3 \mathrm{~cm}$ above ground level, at an angle of $65^{\circ}$ to facilitate the run-off of rainwater into a polyethylene bucket. The bucket was covered with a snap lid and the PVC pipe connection to the container was caulked to seal it from rainwater failing on the lid. Rainfall, temperature, relative humidity, and wind direction were monitored in 15-min intervals with an Adcon A730 weather station (Adcon Telemetry) located near a source pile for both years.

Water samples were collected from each spore trap after a major rainstorm (rain event) of at least $5 \mathrm{~h}$ in duration (17). The amount of rainwater was recorded for each spore trap and a subsample (approximately $500 \mathrm{ml}$ ) was placed into a screw-top plastic container for transport to the lab. The collecting bucket was first rinsed with water three times, $30 \mathrm{ml}$ of a $0.5 \% \mathrm{CuSO}_{4}$ solution was added to inhibit ascospore germination, and then the bucket was repositioned for the next rain event (18). For showers (events less than 5 $\mathrm{h}$ in duration) in between rain events, the bucket was emptied and collected prior to a predicted rainstorm so that the water sample taken from the bucket had ascospores only disseminated from those major rain events. Samples were stored at $6^{\circ} \mathrm{C}$ until processing. Water samples from all source spore traps were evaluated within $24 \mathrm{~h}$ of collection, and the upwind and downwind samples were generally evaluated within 48 to $72 \mathrm{~h}$ after collection.

The procedure for processing rainwater samples was the same as that used by Pinkerton et al. (18). Samples from spore traps were filtered through a $20-\mu \mathrm{m}$ sieve to remove excess debris and then diluted with deionized (DI) water depending on the ascospore concentration. A subsample (30 to $50 \mathrm{ml}$ ) was filtered through a gridded, cellulose nitrate filter (Sartorius A.G.), $25 \mathrm{~mm}$ in diameter with $0.8-\mu \mathrm{m}$ pore size, held in a syringe holder (PALL Life Sciences) with the aid of a plastic syringe (Becton Dickenson). The nitrate filter was then placed on a glass microscope slide, and stained with $0.05 \%$ trypan blue stain (MP Biomedicals LLC) in lactoglycerol (1:1:1 of water, lactic acid, and glycerol). A drop of the stain (approximately $45 \mu \mathrm{l}$ ) was placed on the filter with a cover slip, and then examined under a compound microscope $(\times 100$ to $\times 400)$. The number of ascospores in the four corners of the gridded filter and the middle grid were counted to calculate spores per square meter per hour (18). Viability was ascertained at the same time by counting the ascospores that excluded the trypan blue stain as viable, and ascospores dyed a dark blue as nonviable (9). Filters that were not counted within 10 min of staining were discarded, a fresh subsample was filtered through a new nitrate filter, and the procedure was repeated to minimize the effects of the stain on ascospore viability (9).

Hazelnut tree exposure. Five healthy 2-year-old potted Ennis hazelnut trees were evenly spaced lengthwise adjacent to each of the four spore traps at the six locations on 2 March 2010 and 7
March 2011 (Fig. 1). During propagation, the trees were protected from infection with four applications of propiconazole (Orbit 3.6 EC; Syngenta Crop Protection) at a rate $0.3 \mathrm{ml} / \mathrm{liter}$ of water at 2week intervals starting in mid-March (2009 to 2010) or by exclusion in the greenhouse (2010 to 2011) during the 2-year growth phase. There were no fungicide applications during the experiment. Bud break of the potted trees was on 10 March 2010 and 21 March 2011.

At the end of the season (early June), the potted trees were moved to a greenhouse and monitored for development of EFB symptoms (20). During the incubation period (14 months), the potted trees for both years were fertilized on 2 June 2010 and 20 June 2011 at a rate of $10 \mathrm{~g}$ per $0.03 \mathrm{~m}^{2}$ with $14-14-14$ of N-P-K (Scotts). Herbicide (Herbicide Granules Treflan; Hi-Yield) was applied at a rate of $3 \mathrm{~g}$ per $0.03 \mathrm{~m}^{2}$ ( $0.04 \mathrm{~g}$ of Triflurian) on 3 March 2011, 14 July 2011, and 1 June 2012. Potted trees were evaluated for the number and length of EFB cankers on 21 to 23 July 2011 and 23 to 25 July 2012.

Data analysis. SAS v9.0 (SAS Institute, Inc.) was used for all data analyses. All data were tested for normality and homogeneity of variance. For source spore traps, the number of ascospores in major rain events was totaled for replicates in each season, log transformed, and analyzed by a paired $t$ test for differences between early and late pruning treatments (21). Differences in ascospore numbers between pruning treatments and location of spore traps upwind and downwind of sources were analyzed separately from source spore traps. The numbers of ascospores for major rain events at each upwind and downwind spore trap were totaled for replicates for each season and analyzed by least squares means using a "split-plot-in-time" model (PROC MIXED; 13). Ascospore viability (proportion of viable ascospores to total ascospores) differences between pruning treatments at source spore traps was analyzed with a paired $t$ test, taking the average viability over ma-

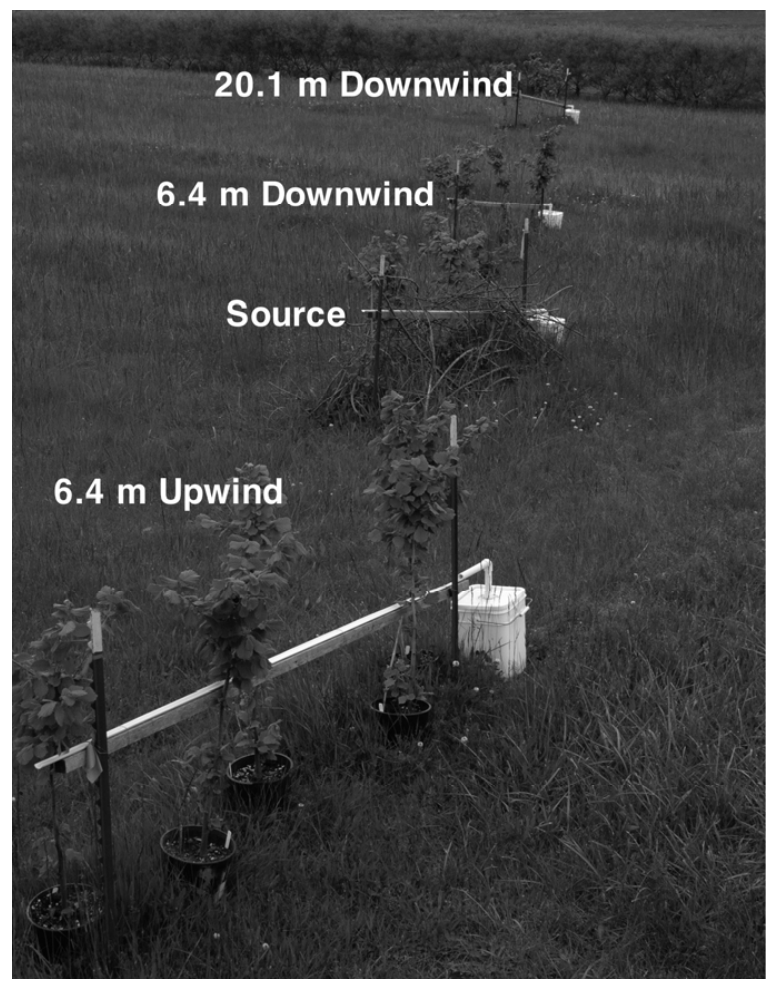

Fig. 1. Each experimental unit consisted of a brush pile of 125 pruned hazelnut branches bearing mature stromata of Anisogramma anomala, the causal agent of eastern filbert blight, and gravity-type spore traps at set distances from each brush pile. Two-year-old potted 'Ennis' hazelnut trees were placed adjacent to spore traps for the entire spring season (March to June); $6.4 \mathrm{~m}$ Upwind = spore trap $6.4 \mathrm{~m}$ southwest of source, Source $=$ spore trap within the brush pile, $6.4 \mathrm{~m}$ Downwind $=$ spore trap $6.4 \mathrm{~m}$ northeast of source, and $20.1 \mathrm{~m}$ Downwind = spore trap $20.1 \mathrm{~m}$ northeast of source. 
jor rain events for replicates during each season (21). Difference in proportion of potted trees with EFB and mean number of EFB cankers per tree between pruning treatments and location (upwind, at source, and two downwind) for each season were analyzed by differences of least squares means using a split-plot-in-time model (PROC MIXED; 13). The proportion of infected potted trees data were not $\log$ transformed; however, the mean number of EFB cankers per tree data were log transformed (based on $\log _{10}[x+1]$ transformation).

\section{Results}

Ascospore collection. Rainwater collection and tree exposure ended on 9 June 2010 and 7 June 2011, respectively. There were 12 major rain events during the monitoring period of 2010 with durations of 18 to $95 \mathrm{~h}$, and rainfall amounts varied from 0.8 to $6.1 \mathrm{~cm}$, with a total seasonal accumulation of $28.2 \mathrm{~cm}$. During these rain events, the prevailing wind direction was southwest $\left(202^{\circ}\right.$ to $\left.248^{\circ}\right)$ $30.5 \%$ of the time at an average of $8.0 \mathrm{~km} / \mathrm{h}$. For 2011 , there were 13 major rain events with durations of 9 to $91 \mathrm{~h}$; rainfall amounts varied from 0.3 to $3.8 \mathrm{~cm}$, with a total seasonal accumulation of $22.1 \mathrm{~cm}$, and the prevailing wind direction was southwest $27.1 \%$ of the time.

The number of ascospores at source spore traps in the early pruning treatment was 580 to 1,718 spores $/ \mathrm{m}^{2} / \mathrm{h}$ in 2010 and

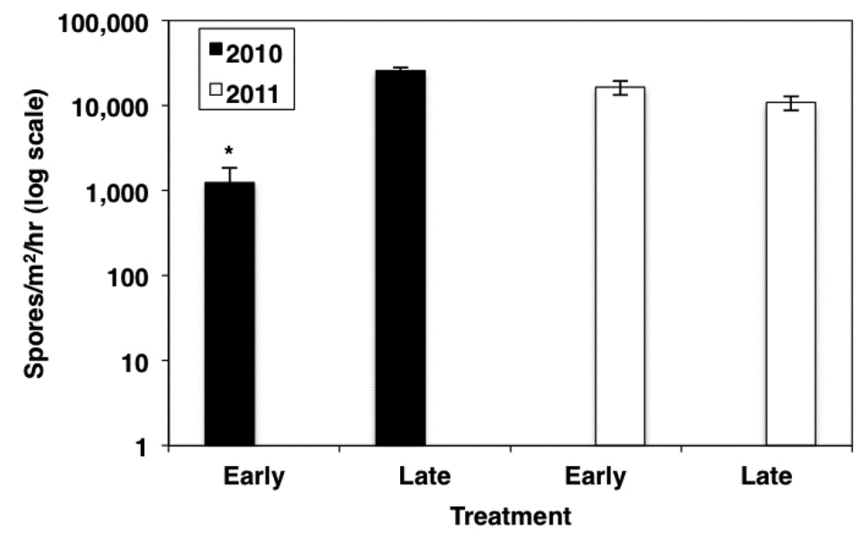

Fig. 2. Log total of Anisogramma anomala ascospores captured in 2010 and 2011 major spring rain events in source spore traps located around early and late pruning treatment source piles. Treatment: Early $=$ pruning treatment having a source with infected branches cut in December, 10 to 12 weeks before bud break; Late $=$ pruning treatment having a source with infected branches cut immediately before bud break. The vertical line on each bar represents the standard deviation. Early-treatment bar with an asterisk was significantly different than the late treatment in 2010 based on a paired $t$ test.

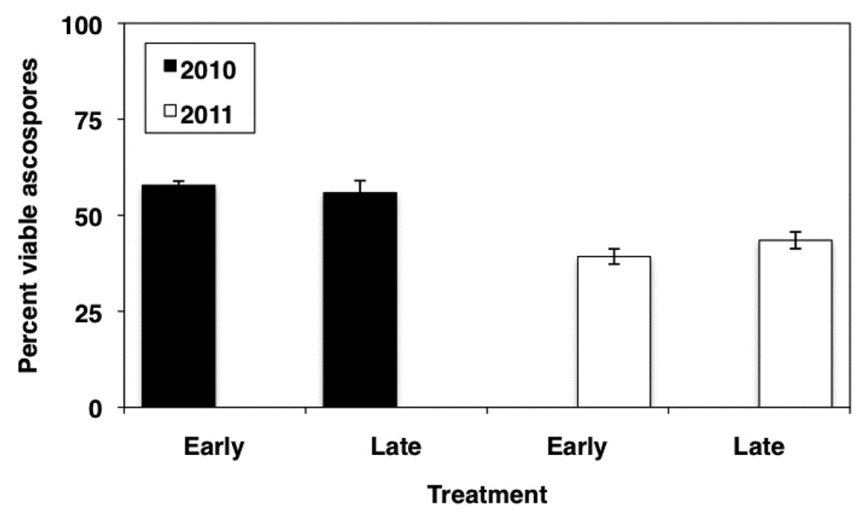

Fig. 3. Average viability of ascospores of Anisogramma anomala captured at source spore traps for major spring rain events from March to June 2010 and 2011. Treatment: Early = pruning treatment having a source with infected branches cut 10 to 12 weeks before bud break and Late = pruning treatment having a source with infected branches cut immediately before bud break. The vertical line on each bar represents the standard deviation.
10,688 to $22,739 \mathrm{spores} / \mathrm{m}^{2} / \mathrm{h}$ in 2011 . The number of ascospores at source spore traps in the late pruning treatment was 24,152 to 28,411 spores $/ \mathrm{m}^{2} / \mathrm{h}$ in 2010 and 7,330 to 17,129 spores $/ \mathrm{m}^{2} / \mathrm{h}$ in 2011. Spore traps positioned within sources of the late pruning treatment collected significantly more ascospores $(P=0.01)$ during the 2010 season than spore traps positioned within sources of the early pruning treatment (Fig. 2). However, the total number of ascospores collected during the 2011 season for the two pruning treatments were not significantly different.

Ascospore viability at source spore traps for the early pruning treatment was 57 to $59 \%$ in 2010 and 36 to $44 \%$ in 2011 . The late pruning treatment ascospore viability was 52 to $58 \%$ in 2010 and 38 to $48 \%$ in 2011. In both seasons, no significant differences were observed in average viability of ascospores collected at source spore traps between the two pruning treatments (Fig. 3). An insufficient number of ascospores was deposited in upwind and downwind spore traps to permit statistical analysis in either year. Although, in 2010, viable ascospores were detected in all 6.4-m downwind spore traps and several 20.1-m downwind spore traps, in 2011 , viable ascospores were detected in only half of the 6.4-m downwind spore traps.

No significant differences were observed in ascospores collected from upwind or downwind spore traps between the two pruning treatments in either year (Fig. 4). However, differences were seen in ascospore counts among the different spore trap locations. The number of ascospores collected in the 6.4-m downwind spore traps for both years was significantly greater $(P \leq 0.01$ for 2010 and $P=$ 0.04 for 2011; no significant interaction was observed between treatment and location) than the number of ascospores collected in the 6.4-m upwind spore traps (Fig. 4). Also, the number of ascospores collected in the 6.4-m downwind spore traps was significantly greater $(P \leq 0.01$ for 2010 and $P=0.01$ for 2011$)$ than the
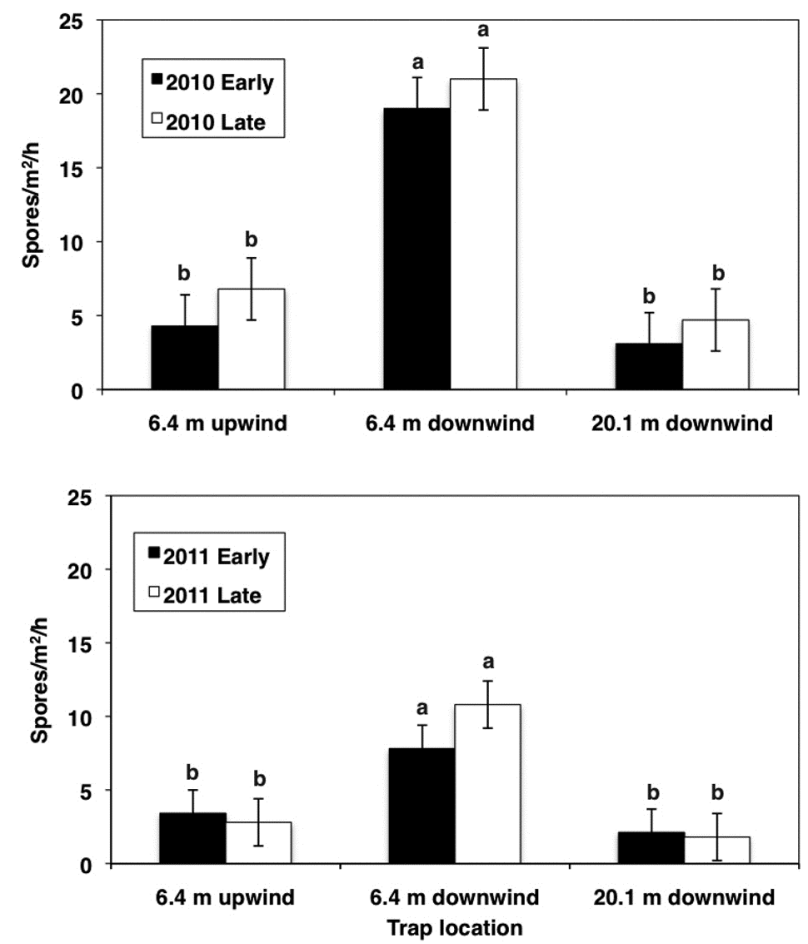

Fig. 4. Total number of Anisogramma anomala ascospores captured in major spring rain events in spore traps located around early and late pruning treatment source piles. Trap Location: $6.4 \mathrm{~m}$ Upwind = spore trap $6.4 \mathrm{~m}$ southwest of source, $6.4 \mathrm{~m}$ Downwind = spore trap $6.4 \mathrm{~m}$ northeast of source, $20.1 \mathrm{~m}$ Downwind $=$ spore trap $20.1 \mathrm{~m}$ northeast of source, Early = pruning treatment having a source with infected branches cut 10 to 12 weeks before bud break, Late = pruning treatment having a source with infected branches cut immediately before bud break. The vertical line on each bar represents the standard deviation. Bars with the same letter do not differ significantly based on differences of least square means using a "split-plot-intime" model in SAS PROC MIXED. 
number of ascospores collected in the 20.1-m downwind spore traps in both years (Fig. 4). There were no detected differences in the number of ascospores in the 6.4-m upwind and 20.1-m downwind spore traps in either season (Fig. 4).

Hazelnut tree exposure. No significant differences were observed in the proportion of potted hazelnut trees with EFB or in the mean number of EFB cankers on potted trees between pruning treatments at any of the locations in 2010 (Fig. 5). All of the potted trees at sources and at locations $6.4 \mathrm{~m}$ downwind became infected during the 2010 season and the proportion of potted trees infected at those two locations was significantly greater $(P<0.01)$ than on potted trees at other locations $(6.4 \mathrm{~m}$ upwind and $20.1 \mathrm{~m}$ downwind; no significant interaction between treatment and location; Fig. 5). The proportion of potted trees infected at 20.1-m downwind locations was significantly greater $(P<0.01)$ than infected potted trees at 6.4-m upwind locations (Fig. 5). The mean number of EFB cankers per tree was greatest on potted trees at sources compared with other potted tree locations $(P<0.01$; Fig. 5). More $(P<0.01)$ EFB cankers per tree were observed in potted trees at 6.4-m downwind locations than potted trees at 20.1-m downwind or 6.4-m upwind locations (Fig. 5). Also, potted trees at 20.1-m downwind locations had significantly more $(P<0.01)$ EFB cankers per tree than those at 6.4-m upwind locations.

Due to mislabeling of potted trees adjacent to downwind locations in one of the replications in 2011, 6.4- and 20.1-m downwind potted tree data were combined for each replication and the proportion of diseased trees was calculated for only "downwind" of source. The proportion of infected potted trees was compared by treatment and direction relative to sources. Directions were desig-
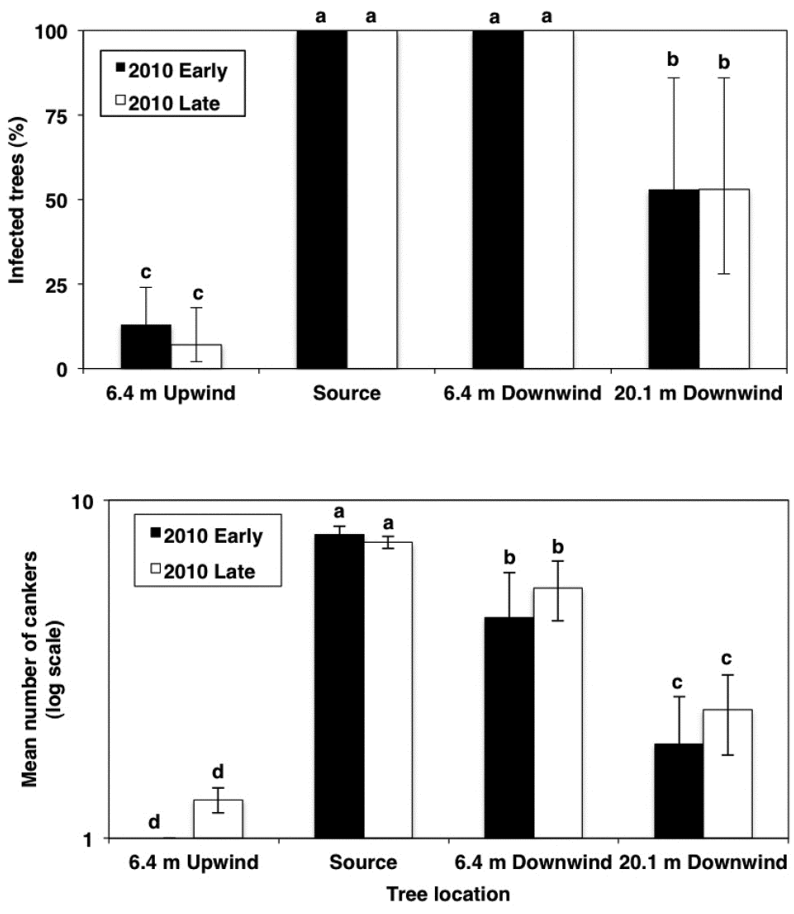

Fig. 5. Percentage of trees with eastern filbert blight (EFB) and mean number of EFB cankers per tree in 2-year-old potted European 'Ennis' hazelnut trees placed adjacent to the different spore trap locations from March to June 2010. Tree location: $6.4 \mathrm{~m}$ Upwind = five potted trees placed adjacent to spore trap $6.4 \mathrm{~m}$ southwest of source, Source $=$ five potted trees placed adjacent to spore traps within the pile of pruned hazelnut branches bearing mature stromata of Anisogramma anomala, $6.4 \mathrm{~m}$ Downwind $=$ five potted trees placed adjacent to spore trap $6.4 \mathrm{~m}$ northeast of source, $20.1 \mathrm{~m}$ Downwind = five potted trees placed adjacent to spore trap $20.1 \mathrm{~m}$ northeast of source, Early = pruning treatment having a source with infected branches cut 10 to 12 weeks before bud break, Late = pruning treatment having a source with infected branches cut immediately before bud break. The vertical line on each bar represents the standard deviation. Bars with the same letter do not differ significantly based on differences of least square means using a "split-plot-in-time" model in SAS PROC MIXED. Mean number of cankers analysis based on $\log _{10}(x+1)$ transformation. nated as upwind of source, source, and downwind of source. No significant differences were observed between pruning treatments for proportion of potted trees infected at any of those directions in the second season (Fig. 6, no significant interaction between treatment and direction). All five potted trees within the source locations were infected (Fig. 6) and the proportion of potted trees infected was significantly greater $(P<0.01)$ for sources than for the upwind or downwind directions. The proportion of infected potted trees in the downwind direction was significantly greater $(P<$ 0.01 ) than that for the upwind direction (Fig. 6). The number of EFB cankers per tree was greatest on potted trees at sources compared with potted trees located in the upwind and downwind directions $(P<0.01)$. Like 2010 , EFB cankers per tree were significantly more on potted trees downwind of sources than upwind of sources $(P=0.04$; Fig. 6$)$ but the 2011 downwind potted trees had fewer multiple cankers.

\section{Discussion}

Diseased hazelnut branches from early or late pruning treatments were sources of viable $A$. anomala ascospores. The cumulative proportion of total ascospores at source spore traps was similar to results from a previous seasonal discharge study in which cankered branches still attached to trees were monitored (18). Simply cutting branches with cankers from trees at different times during the dormant season did not consistently reduce sporulation of this obligate biotrophic fungus in the field.

The observed decrease in ascospore numbers for the early treatment in 2010 may have been influenced by temperature. From January (when early treatments were put into brush piles) to the
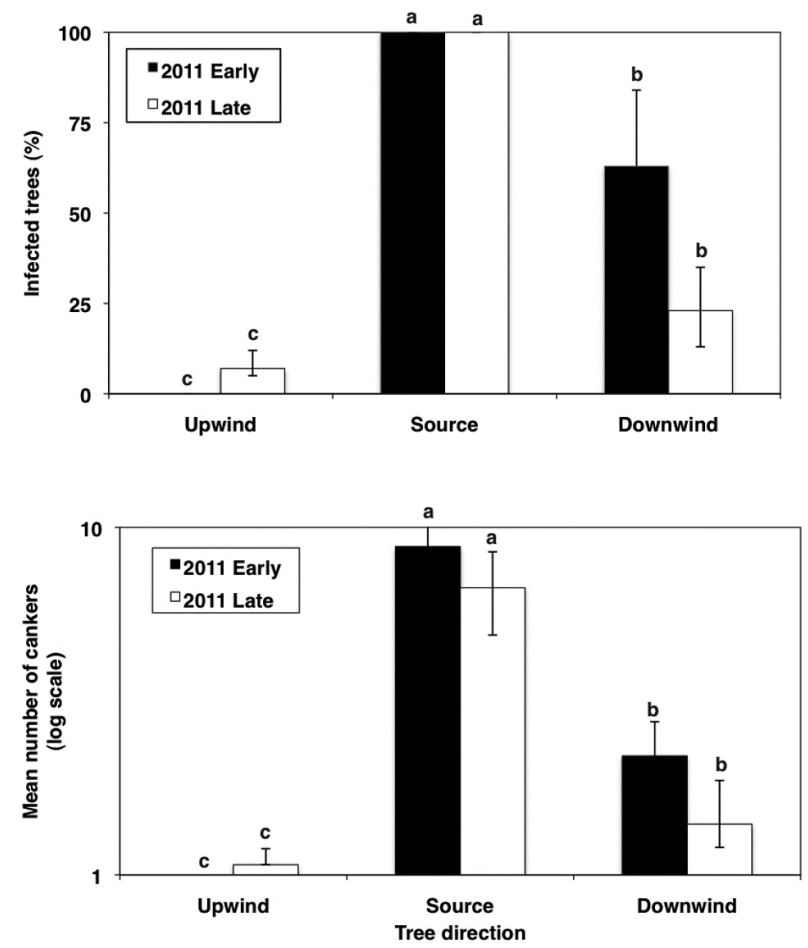

Fig. 6. Percentage of trees with eastern filbert blight (EFB) and mean number of EFB cankers per tree in 2-year-old potted European hazelnut trees placed adjacent to the different spore trap locations from March to June 2011. Tree direction: Upwind $=$ five potted trees placed adjacent to spore trap $6.4 \mathrm{~m}$ southwest of source, Source $=$ five potted trees placed adjacent to spore traps within the pile of pruned hazelnut branches bearing mature stromata of Anisogramma anomala, Downwind $=$ five potted trees placed adjacent to spore trap 6.4 and $20.1 \mathrm{~m}$ northeast of source (total of 10 potted trees), Early = pruning treatment having a source with infected branches cut 10 to 12 weeks before bud break, Late = pruning treatment having a source with infected branches cut immediately before bud break. The vertical line on each bar represents the standard deviation. Bars with the same letter do not differ significantly based on differences of least square means using a "split-plot-intime" model in SAS PROC MIXED. Mean number of cankers analysis based on $\log _{10}(x+1)$ transformation. 
beginning of March 2011 (when late treatments were put into brush piles), the temperatures were, on an average, $3^{\circ} \mathrm{C}$ colder than that same period in 2010. Year-to-year variability in ascospore release was also observed on excised branches of sour cherry trees infected with black knot that were cut at various times throughout the spring (14). McFadden-Smith et al. (14) found that branches cut earlier in the spring in years with warmer temperatures had greater ascospore numbers. Brush piles of the early treatment may have released the majority of their ascospores before monitoring began in March due to the warmer temperatures in 2010 (18).

Contrary to expectations, the proportion of viable ascospores obtained from early-pruned branches was not significantly different from late-pruned branches. Ascospore viability may be influenced by the composition of the canker. Histological studies have shown that $A$. anomala asci are surrounded by viscous fluid in the perithecium and ascospores were susceptible to desiccation in the environment when outside of the asci $(7,15)$. Squash mounts of perithecia stained with trypan blue indicated that ascospores outside the ascus but still within the viscous fluid stayed viable for at least an hour, whereas ascospores extracted out of the ascus (away from the viscous fluid) stained and mounted on a slide would lose viability within 10 to $15 \mathrm{~min}$ (S. Heckert, unpublished data). The viscous fluid that surrounds ascospores in the perithecium may have allowed them to retain viability until they were released into the environment even though the branches bearing the cankers had been detached from the tree for several months.

Greater numbers of ascospores at the 6.4-m downwind spore traps (regardless of treatment) compared with the 20.1-m downwind spore traps in 2010 suggest a spore dispersal gradient away from sources that year. Also, greater ascospore numbers in our downwind spore traps compared with upwind spore traps for both years indicated that ascospores were being dispersed on the prevailing storm track. Pinkerton et al. (15) observed ascospore gradients downwind of sources in their study of both diseased orchards and "mini-orchards" consisting of 121 trees (11 trees in 11 rows with $3 \mathrm{~m}$ between rows and a line of hazelnut trees bearing sporulating cankers $3 \mathrm{~m}$ upwind of the first row). The ascospore gradient in diseased orchards was shallower than in the mini-orchards, and they concluded that it was due to the strength of the source (21). Our observed spore dispersal gradient in 2010 was steep because the brush piles were a weaker source than the mini-orchards.

Greater incidence and severity of EFB on potted trees exposed at sources regardless of pruning treatment indicated the presence of sufficient viable inoculum to cause multiple infections. High disease incidence downwind of sources was also observed, suggesting that viable ascospores were being disseminated outside of the rain splash dispersal range. In the mini-orchard experiments of Pinkerton et al. (15), disease was found in 2-year-old hazelnut trees $33 \mathrm{~m}$ away from the source of inoculum. It was concluded that there was strong evidence for the active discharge of ascospores. The mechanism behind the discharge of ascospores was not explored in our study but cut branches were either forcibly discharging ascospores (2) or ascospores were rain splashed strongly enough (5) to break the laminar boundary layer and to consistently be transported downwind (8). Source brush piles were placed in such a way that they were exposed to wind from all directions, and Aylor (1) noted that the access of spores to wind was a key to active dispersal.

There were fewer diseased potted trees downwind in 2011 compared with 2010. Variation in wind direction and speed during the major rain events between these 2 years might have been the contributing factors. We analyzed the proportion of wind direction and speed (from the southwest) from late March to the beginning of May (the typical 8-week fungicide spraying time; 11). The wind was from the southwest for $45 \%$ of the time in 2010 at an average speed of $10.4 \mathrm{~km} / \mathrm{h}$ compared with $25 \%$ from the southwest at an average speed of $7.7 \mathrm{~km} / \mathrm{h}$ in 2011 . The greater proportion of wind coming from the southwest and at greater speeds in 2010 may be the reason for more infection on potted hazelnut trees downwind of sources.
Our findings indicate that diseased hazelnut branches pruned either in December or before bud break in March can be inoculum sources of EFB in orchards. It is recommended that growers continue to destroy all pruned diseased branches before hazelnut bud break in March. Growers who are unable to destroy pruned diseased branches are advised to position diseased brush piles downwind of their orchards. These small (1-by-1-m) diseased brush piles, regardless of date cut, were significant sources of inoculum that infected susceptible hazelnut tissue at least $20 \mathrm{~m}$ away. Further research could determine whether chipping or grinding colonized branches would eliminate inoculum in hazelnut orchards.

\section{Acknowledgments}

This research was supported, in part, by the Oregon Hazelnut Commission. We thank J. K. Stone, K. Johnson, and J. L. Parke for critical comments during preparation of this manuscript.

\section{Literature Cited}

1. Aylor, D. E. 1986. A framework for examining inter-regional aerial transport of fungal spores. Agric. For. Meteorol. 38:263-288.

2. Aylor, D. E., and Anagnostakis, S. L. 1991. Active discharge distance of ascospores of Venturia inaequalis. Phytopathology 81:548-551.

3. Clark, C., and Coba, K. 2011-2012 Oregon agriculture and fisheries statistics. NASS, USDA. http://www.oregon.gov/ODA/docs/pdf/pubs/agripedia. stat.pdf

4. Downing, K. Oregon open burning guide. Oregon Department of Agriculture. www.deq.state.or.us/aq/factsheets/04-AQ-005-OpenBurnEng.pdf

5. Fitt, B. D. L., and Lysandrou, M. 1984. Studies on the mechanisms of splash dispersal of spores, using Pseudocercosporella herpotrichoides spores. Phytopathol. Z. 111:323-331.

6. Fitt, B. D. L., and Nijman, D. J. 1983. Quantitative studies on dispersal of Pseudocercosporella herpotrichoides spores from infected straw by simulated rain. Neth. J. Plant Pathol. 89:198-202.

7. Gottwald, T. R., and Cameron, H. R. 1979. Studies in the morphology and life history of Anisogramma anomala. Mycologia 71:1107-1126.

8. Gregory, P. H. 1973. The Microbiology of the Atmosphere, 2nd ed. Halsted Press Books, New York.

9. Heckert, S., Pscheidt, J. W., and Stone, J. K. 2013. A quick and simple method to evaluate Anisogramma anomala ascospore viability. Plant Health Progress. Online publication. doi:10.1094/PHP-2013-0509-09-RS

10. Heckert, S., Pscheidt, J. W., Stone, J. K., and Cluskey, S. A. 2011. Ascospore viability and dispersal from pruned branches infected with $A n-$ isogramma anomala. (Abstr.) Phytopathology 101:S71.

11. Johnson, K. B., Mehlenbacher, S. A., Stone, J. K., Pscheidt, J. W., and Pinkerton, J. N. 1996. Eastern filbert blight of European hazelnuts: it's becoming a manageable disease. Plant Dis. 80:1308-1316.

12. Johnson, K. B., Pscheidt, J. W., and Pinkerton, J. N. 1993. Evaluation of chlorothalonil, fenarimol, and flusilazole for control of eastern filbert blight. Plant Dis. 77:831-837.

13. Littell, R. C., Milliken, G. A., Stroup, W. W., Wolfinger, R. D., and Schabenberger, O. 2006. SAS for Mixed Models, 2nd ed. SAS Institute, Cary, NC.

14. McFadden-Smith, W., Northover, J., and Sears, W. 2000. Dynamics of ascospore release by Apiosporina morbosa from sour cherry knots. Plant Dis. 84:45-48.

15. Pinkerton, J. N., Johnson, K. B., Aylor, D. E., and Stone, J. K. 2001. Spatial and temporal increase of eastern filbert blight in European hazelnut orchards in the Pacific Northwest. Phytopathology 91:1214-1223.

16. Pinkerton, J. N., Johnson, K. B., Mehlenbacher, S. A., and Pscheidt, J. W. 1993. Susceptibility of European hazelnut clones to eastern filbert blight. Plant Dis. 77:261-266.

17. Pinkerton, J. N., Johnson, K. B., Stone, J. K., and Ivors, K. L. 1998. Factors affecting the release of ascospores of Anisogramma anomala. Phytopathology 88:122-128.

18. Pinkerton, J. N., Johnson, K. B., Stone, J. K., and Ivors, K. L. 1998. Maturation and seasonal discharge pattern of ascospores of Anisogramma anomala. Phytopathology 88:1165-1173.

19. Pinkerton, J. N., Johnson, K. B., Theiling, K. M., and Griesbach, J. A. 1992. Distribution and characteristics of the eastern filbert blight epidemic in western Oregon. Plant Dis. 76:1179-1182.

20. Pscheidt, J. W., Grimaldi, P., and Penhallegon, R. 2008. The eastern filbert blight epidemic in the Pacific Northwest: Survey vs. biology. Proc. Nut Grow. Soc. Oreg. Wash. British Coloumbia 93:38-50.

21. Ramsey, F. L., and Schafer, D. W. 2002. A Course in Methods of Data Analysis, Second Edition. Duxbury, Pacific Grove, CA.

22. Stone, J. K., Johnson, K. B., Pinkerton, J. N., and Pscheidt, J. W. 1992. Natural infection period and susceptibility of vegetative seedlings of European hazelnut to Anisogramma anomala. Plant Dis. 76:348-352.

23. Stone, J. K., Pinkerton, J. N., and Johnson, K. B. 1994. Axenic culture of Anisogramma anomala: evidence for self-inhibition of ascospore germination and colony growth. Mycologia 86:674-683. 